\title{
The erosion of African communal values: a reappraisal of the African Ubuntu philosophy
}

\author{
Nonceba Nolundi Mabovula' \\ Centre For Learning and Teaching Development, Walter Sisulu University, \\ Nelson Mandela Drive Campus, Mthatha \\ nmabovula@yahoo.co.uk
}

\begin{abstract}
The paper, which exploits conceptual analysis techniques, interrogates an African notion of a 'community' as embodied in the ideas of 'Umntu ngumntu ngabantu.' The problem the article seeks to address is the erosion of community values. The study intends to explore the question: How can we retrieve the communal cultural values of tolerance, humanity, respect and some of common elements of our cultural treasures of Ubuntu that African communities used to be proud of? Using the philosophy of Ubuntu as a hermeneutic key, I argue that any member of a community whose personal life is guided by Ubuntu could be said to have embraced the core humanistic attributes of Ubuntu. These are being caring, humble, thoughtful, considerate, understanding, wise, generous, hospitable, socially mature, socially sensitive, virtuous, and blessed: character attributes that veer away from confrontation towards conciliation. The paper is based on a small scale survey, which exploited an open ended questionnaire in its data collection. Data revealed that despite major constraints such as poverty and scarcity of resources, crime, substance abuse and many others, family members are still willing to help and support each other. Finally, the study suggests that the values of Ubuntu, if consciously harnessed, can play a major unifying role in the process of harmonising the South African/African nation(s).
\end{abstract}

Key words: Community, communalism, African humanity, African philosophy, Ubuntu,

\section{Introduction}

The term communitarianism is derived from the word 'community', and it refers to any philosophical standpoint that defines a person in the context of social bonds and cultural traditions rather than through individual traits (Daly 1994). Another community view which I am keen to highlight in this paper is the one put forward by Ramose (2002a), who maintains that an African community is an ongoing dynamic association of men and women, who have a special commitment to one another and have developed a distinct sense of their common life. The common life, in this sense, is perceived as any public discursive space which members construct through action - in concert. In this context, the history of a person's life is the story of his or her transactions with the community's material and moral worlds, which, in effect, is the story of his or her relations with particular sets of social goods. This is called a social contract in which an individual's choice of way of life is a choice constrained by the community's pursuit of shared ends.

Waghid, Van Wyk, Adams and November (2005: 108) maintain that the slogan "your child is mine [and] my child is yours" has a particularly African flavour to it and in many ways epitomises the sense of community so prevalent in African society. In this sense the child is held to be the property of the community and it is the community members who are expected to see to it that the individual child becomes a significant member of that particular community, an asset to all. Barber (1998) believes that people envisage civil society as complex social relations that tie people together. The initial social stratum is constructed first of all into families and kinship, associations like clans, and then into clubs, neighbourhoods, communities, congregations, and more extended social hierarchies. This is the central notion of a community where people work together to create peace and love.

Another essence of African cultural existentialism the study unravels is African communalism. Khoza (2005:266) describes communalism as "a concept that views humanity in terms of collective existence and intersubjectivity, serving as the basis for supportiveness, cooperation, collaboration and solidarity". In similar conceptual context, Gyekye (1987) defines African communalism as a kinship-oriented social order, which is informed by an ethic of reciprocity. In a communal social order one is brought up with a sense of solidarity with large groups of people. During the course of this "cohabitation" (Khoza, 2005:266) ${ }^{2}$ Gyekye (1987) maintains that one comes to see one's interests as being bound up with the interests of the group over a great number of issues of life and well-being. This sense of community, according to Gyekye, is a characteristic of African life and indeed, to many Africans, this communal efficacy defines Africanness. In the context of Gyekye's definition, this form of communalism signifies the human person as an inherently communal being

I. Nonceba Nolundi Mabovula, PhD, is Senior Researcher Associate Centre For Learning and Teaching Development Walter Sisulu University, South Africa

2. In his Let Africa Lead, Sunninghill: Vezubuntu, 2005, p. 266, Reuel J. Khoza defines 'cohabitation' as 'the proclivity to live with others harmoniously, not only in terms of shared space, but also accommodating other people's ideas and seeking to understand before proceeding to persuade.' 
embedded in a context of social relationships and interdependence, and never as an isolated, atomistic individual. In African community, people view themselves and what they do as equally good to others as to themselves.

Traditional African cultural practices are performed by members, clans and relatives in their socio-ethical settings. Kwasi Wiredu (in Waghid et al. 2005) also observes that African traditional cultures are characteristically communalistic (or, if you like, communitarian). Wirendu further asserts that in the African context, communitarianism refers to a culture that is a form of life, exemplifying a certain conception of the role and significance of the community in the life of individuals in society. Gyekye (2002) notes that the communal or communitarian attributes of African socio-ethical thought are reflected in the communitarian features of the social structures of African society. This view is taken further by Waghid et al. (2005), who comment on Geykye's definition of community. Waghid et al. (2005) postulate that Geykye sees community not as a mere association of individual persons, whose interests and ends are contingently congruent but as a group of persons linked by interpersonal, biological and/or non-biological bonds. Geykye concludes that the members of a community also consider themselves primarily as members of the group that have common interests, goals, and values. According to Mogobe Ramose (2002b), the notion of remaining in touch in a community is not merely a sociological perception but a moral viewpoint.

A good example one can think of is how things were (and still are) done in indigenous African settings in which people come together whenever problems arise, where ideas are shared, solutions are sought and found by all community members in a given real-life situation. The social supportive measures listed above are carried out so as to promote peace, love, respect, and working together in social harmony. However, community members no longer trust each other. Lack of discipline, violence, crime and aggressive behaviour in society become the accepted facts of life. Regardless of fluctuations in rates of incidence and categories, the erosion of traditional codes of humanism continues to create an ongoing challenge to African communities. For instance, the emergence of a new anti-traditional African phenomenon of xenophobic incidents among Africans has compounded the fast erosion of efficacy of Ubuntu. Statistics of cases of xenophobic violence are repeatedly reported by the South African media and researchers. These are not the only destructive factors that undermine African traditional values that promote harmony and a sense of pride in African cultural heritage.

The study conducted during the period 2004-2008 reveals that school children from different kinds of communities show very little respect for their principals in schools, parents, educators, elders, and friends. Many of them fail to meet commitments in school work; they do not keep time and promises, and fail to do their homework. Besides the above negative behavioural attitudes displayed by school children towards authority, they also carry knives and guns in school and in communities. The prevailing worsening deterioration of Africa's social fabrics outlined above is endorsed by Waliggo's (2005) study. Waliggo (2005: 9) observes that public morality is very weak in Africa. For him the contemporary African society does not take the current economic immorality and crimes which involve fraud, embezzlement of public funds, corruption and abuse of office seriously. Instead of exposing crimes committed against the state, Waliggo argues, many people tend to praise and protect their own relatives and friends who perpetrate economic crimes against the state to uplift their own areas and to enrich their people.

Besides the concealment of crimes and corrupt practices against the state by family members, recent reports in media further indicate a surge in shootings, stabbings, rapes and robberies. The South African media release statistics of cases of violence and crime committed in communities on a daily basis. In short, these incidences of violence, like violence in society, seem to run in cycles. These cycles appear to mirror the trends of violence in larger society and communities. In addition to incidences of violence, community members have now developed an individualistic philosophy, which.tends to run counter to many traditional values. Khoza (in Roux \& Coetzee 1994: 3) defines individualism as "that political and social philosophy that places high value on the freedom of the individual and generally stresses the self-directed, selfcontained and comparatively unrestrained individual or ego".

This paper poses the question: What could help bring back communal cultural values of tolerance, humanness, respect and some of the common priceless features of Ubuntu that the African communities used to be proud of? I am conscious of the fact that the societal culture of tolerance does not develop in a vacuum. However, African communities used to and still advocate the advancement of Ubuntu. By writing this paper, I wish to promote the value system embodied in Ubuntu and hope that everyone who reads this paper revisits the Ubuntu concepts during these turbulent times in the history of our nation. This paper is aimed at examining the following objectives:

- To investigate the African philosophy of Ubuntu

- To explore the embedded conceptual features of Ubuntu

- To highlight the South African perspective of Ubuntu and its relevance to South African communities

- To unravel problems that hamper the implementation of Ubuntu and

Inkanyiso, Jnl Hum \& Soc Sci 20I I, 3(I) 
- To suggest the way forward for African communities

How the Ubuntu philosophy shapes and informs African cultural values is the next preoccupation of this paper.

\section{The philosophy of Ubuntu}

Ubuntu is difficult to define and a plethora of definitions, each emphasising different elements of the concept, exist. According to Roux \& Coetzee (1994: 135), scholars such as Reuel Khoza, E.N Chikanda, Joe Teffo, Nono Makhundu, Sisho Maphisa and Augustine Shutte all attempt to define Ubuntu. According to Battle (1996: 99) the concept ubuntu originates from the Xhosa expression 'Umuntu ngumntu ngabanye abantu', which means that each individual's humanity is ideally expressed in relationship with others. Ubuntu consists of the prefix ubu-and the stem ntu-ubu evokes the idea of being in general. Thus, ubu-ntu is the fundamental ontological and epistemological category in the African thought of the Bantu-speaking people.

Khoza (in Roux \& Coetzee 1994) describes Ubuntu as an African view of life - an African world-view. He argues that the distinctive collective consciousness of Africans is manifested in their behaviour patterns, expressions and spiritual selffulfilment in which values such as the universal brotherhood of Africans, sharing and treating other people as humans, are concretised. His basic idea of universal brotherhood is echoed by other African thinkers in ideas such as sensitivity to the needs and wants of others, the understanding of others' frames of reference and man as a social being.

In his recent groundbreaking work Let Africa Lead, Khoza (2005:269) defines Ubuntu as "an African value system that means humanness or being human, a worldview characterised by such values as caring, sharing, compassion, communalism, communocracy and related predispositions." Khoza adds that "Although it [Ubuntu] is culturally African in origin, the philosophy can have universal application." The collective consciousness ${ }^{3}$ advocated by Ubuntu thinkers involves notions such as universal brotherhood and sharing which for Mbigi means "participation". From this view Mbigi (1997) develops a network of concepts such as "group solidarity", "compassion", "respect", "dignity", and "collective unity" to convey his idea of Ubuntu. This has been stated clearly in Khoza's view of "collective consciousness", which involves universal brotherhood, sharing and treating other people with respect. The sharing characteristic is very important for most Ubuntu philosophers - an attribute, which is also Mbigi's starting point in developing his views on Ubuntu. Roux and Coetzee (1994) assert that Mbigi bases his model on four principles which he derives from the Ubuntu view of life:

- Morality which involves trust and credibility.

- Interdependence which concerns the sharing and caring aspect that is co-operation and participation.

- Spirit of man which refers to human dignity and mutual respect that insists that human activity should be persondriven and humanness should be central, and lastly

- Totality, which pertains to continuous improvement of everything by every member.

In the context of the African spirit of Ubuntu, Khoza (2005:xxi) observes that Ubuntu "constitutes the spiritual cradle of African religion and culture [and] finds expression in virtually all walks of life - social, political and economic." In this sense, the African spirit of Ubuntu should then be regarded as one of the origins of the development of a human rights culture in South Africa and the rest of African continent. The philosophy of Ubuntu espouses a fundamental respect in the rights of others, as well as a deep allegiance to the collective identity. More importantly, Ubuntu regulates the exercise of individual rights by emphasising sharing and co-responsibility and the mutual enjoyment of rights by all. It also promotes good human relationships and enhances human value, trust and dignity. The most outstanding positive impact of Ubuntu on the community is the value it puts on life and human dignity, particularly its caring attitude towards the elderly, who played and continue to play an important communal role in consolidating Ubuntu values.

African societies place a high value on human worth, but it was humanism that found expression in a communal context rather than individualism (Teffo 1998: 3). According to Mbiti (1970: 108), "Whatever happens to the individual happens to the whole group and whatever happens to the whole group happens to the individual". This leads to social harmony and cohesion starting at the family and cultural community, circling out to the global community (Le Roux 2000). By perceiving the individual as being in the centre of this greater whole, the philosophy of Ubuntu may perhaps be described as African humanism.

3. Khoza (2005:266) describes 'collective consciousness' as "a term coined by the psychologist, Carl Jung, which refers to the archetypal imagery that haunts the dreams and subconscious life of humankind. Communities manifest the collective unconscious by creating heroes: the underlying psychological archetype of leader." 


\section{Characteristic features of Ubuntu}

\section{(a) Humanity}

The tenets of humanity/humanism shape and inform the African fight for emancipation from colonialism. The question that needs to be interrogated is what is the relationship between Ubuntu and humanity/humanism? Firstly, Letseka (2000) identifies the notion of Botho or Ubuntu (humanism) as pervasive and fundamental to African socio-ethical thought. Perceived as an important measure of human well-being or humanness flourishing in traditional African life, Ubuntu/ humanism illuminates the communal rootedness and interdependence of persons, and highlights the importance of human relationships. Letseka treats Botho or Ubuntu as normative because it encapsulates moral norms and virtues such as kindness, generosity, compassion, benevolence, courtesy, and respect and concerns for others (Letseka 2000).

According to Letseka, a person has a duty to give the same respect, dignity, value and acceptance to each member of the community. Moreover, the person who lives in accordance with the principles of Ubuntu in a community is said to embrace its major tenets. The core Ubuntu characteristics are being caring, humble, thoughtful, considerate, understanding, wise, generous, hospitable, socially mature, socially sensitive, virtuous and blessed - enduring humanistic attributes that move away from confrontation towards conciliation. The above qualities are the essential ingredients that enable people to work together.

Secondly, Ramose (2002a) argues that Ubuntu can be understood as being human (humanness). Key concepts used to describe Ubuntu are forgiveness, recognition, humaneness, being respectful and being polite. Ramose believes that interdependence, collective consciousness and a communalist worldview are of the utmost importance in the African way of life. For Ramose, community ethos requires tolerance, understanding and respect towards all individuals in interpersonal relationships, in relations between the individual and the group of which he/she forms part, between groups, between such groups and larger communities which are the component forces between different communities: interconnected social strata that eventually encompass all ties of humanity. In this context, Ubuntuism may thus be observed at its most basic level in individual interactions and in the operation of small groups (such as families): an interaction that reflects a view of humanity generally. The communal practice of black people is almost, but not all inclusively, similar to the universal notion.

Thirdly, Ubuntu has been called African humanism because it emphasises the value of human dignity irrespective of a person's usefulness. It expresses the idea that a person's life is meaningful only if he or she lives in harmony with other people because an African person is an integral part of society. For Chikanda as mentioned by Roux and Coetzee (1994), Ubuntu, which she sees as African humanism, involves alms-giving, sympathy, caring, sensitivity to the needs of others, respect, consideration, patience and kindness. Developing human potential requires, according to Nono Makhundu in Roux and Coetzee (1994), traits such as warmth, empathy, reciprocity, harmony, co-operation and a shared world-view, which make up the Ubuntu culture. Its spirit emphasises respect for human dignity, marking a shift from confrontation to conciliation.

Fourthly, humanity in this view is seen as a characteristic of the whole species because humanity signifies different elements of the human species. African humankind constitutes one family. Thus, one gains humanity by entering into this relationship with other members of the family. This means that to be human is to affirm one's humanity by recognising the humanity of others and, on that basis, establishing human respect with them. It is therefore logical to contend that to denigrate and disrespect other human beings is (in the first place) to denigrate and disrespect oneself, if it is accepted that oneself is a subject worthy of dignity and respect. A person's (own) humanity is seen to be a gift. These are some of the values we grew up with as Africans in our community.

The individual has a social commitment to share his/her relationship with others. The individual experiences that could be shared with others include his/her record in terms of kindness and good character, generosity, hard work, discipline, honour and respect, and living in harmony (Teffo 1998). The humanness referred to here finds expression in a communal context. However, while the values that the word Ubuntu encapsulates are not themselves unique to African thought, their significance for a society is arguably much more pronounced in African communities. The interdependence of community members in turn leads to the recognition that individuals not only exercise their rights communally, but also have certain duties towards the community as a whole as well as towards other individual members. According to Venter (2004), Ubuntu is a concrete manifestation of the interconnectedness of human beings and the embodiment of African culture and life style.

\section{(b) Tolerance}

Tolerance is a value to be achieved by deepening people's understanding of the origins, evolution and achievements of humanity on the one hand and through the exploration of that which is common and diverse in cultural heritage on the other. Disagreements need not cause harm if there is tolerance and respect for the other's viewpoint in the community Inkanyiso, Jnl Hum \& Soc Sci 20I I, 3(I) 
structure. Tolerance is the idea that one must not disregard other people's points of view (not even about important moral issues). In addition, the value of tolerance has become even more important now that we live side by side with people who are very different from us. If a society is not tolerant, then there cannot be true freedom. Highlighting the importance of tolerance does not suggest that it is the only value that community members should live by, or even that it is the most important. However, when communities make moral evaluations, it is important that these evaluations evolve from a continuous discussion and debate between various role-players in the community. Another important characteristic that nourishes the community structure is that of respecting each other.

\section{(c) Respect}

In the great context of ideas that best symbolises enlightened humanity, respect, in addition to intelligence and tolerance, is probably the most essential quality, more especially for people working together for a common cause. As a value, 'respect' is not explicitly defined in the Constitution but it is implicit in the way the Bill of Rights governs not just the state's relationship with citizens but citizens' relationships with each other. How can I respect you if you do not respect me? Respect is an essential precondition for communication, for teamwork and for productivity: a vital tool for addressing communal problems. An institution cannot function if mutual respect does not shape and inform its activities. In some of the most important international declarations that South Africa has ratified, and which are therefore legally binding on our country, South Africans have committed themselves to the values of respect and responsibility. The Universal Declaration of Human Rights also states that education shall be directed to the full development of the human personality and to the strengthening of respect for human rights and fundamental freedoms.

\section{South African perspective of Ubuntu}

In the South African context, Ubuntu is seen as a notion with particular resonance in the building of democracy. According to Le Grange (in Waghid et al. 2005: I3I) the term Ubuntu has gained prominence in post-Apartheid South Africa. Justice Mokgoro likens Ubuntu to the English word "humanity" and the Afrikaans word "menswaardigheid", and argues that it embraces both section 9 (the right to life), and section 15 (the right to human dignity) of the Constitution's Bill of Rights. The Bill of Rights was born out of a long struggle against colonial oppression and apartheid. In Makwanyane (I995), Justice Sachs said that the concept of Ubuntu should be invoked when the Bill of Rights is applied to restore dignity to ideas and values that have long been suppressed or marginalised. Born out of the African spirit of Ubuntu, the Bill of Rights is part of the African Renaissance, the rebirth of those African/South African values which have been suppressed or marginalised by colonial powers and institutions.

The Bill of Rights should therefore be seen as the attempt to give expression to the values associated with Ubuntu. In the 1990s, Ubuntu received recognition, from the Interim Constitution and the post-preamble to the interim Constitution (1993) includes the following lines: "The adoption of this constitution lays the secure foundation for the people of South Africa and enables them to transcend the divisions and strife of the past, which generated gross violations of human rights, the transgression of humanitarian principles into violent conflicts and a legacy of hatred, fear, guilt and revenge". In the postscript to the interim constitution for example, Ubuntu is explicitly mentioned as being the source of the underlying values of the new South Africa. It (Ubuntu) is listed along with the constitution, human rights and a legacy of hatred. In this formulation, Ubuntu is aligned into positive values of understanding and reparation, and contrasted with vengeance, retaliation, and victimisation. Justice Mokgoro cited by Makwanyane refers to Ubuntu as one shared value that runs like a golden thread across cultural lines and then proceeds to the following definition.

Generally, ubuntu translates as humaneness. In its most fundamental sense it translates as personhood and morality. Metaphorically, it expresses itself in Umntu ngumntu ngabantu (a person is a person because of other people), describing the significance of group solidarity on survival issues so central to survival of communities. While it envelops the key values of group solidarity, compassion, respect, human dignity, conformity to the basic norms and collective unity, in its fundamental sense it denotes humanity and morality (Makwanyane 1995: 308).

The source of indigenous values to which the passage is referring is the concept of Ubuntu. In South Africa, Ubuntu has become a notion with particular resonance in the building of a democracy. In part, its prominence might be understood as an attempt to re-discover African cultural values eroded by both colonialism and apartheid. Although Ubuntu is part of the South African "rainbow heritage" and the society is multi-ethnic and multicultural, the Ubuntu philosophy might have operated and still be operating differently in diverse community settings of the "rainbow" nation.

Another South African perspective on Ubuntu is provided by Sebidi, who warns that the collective values of Ubuntu cannot be compromised. For him, Ubuntu is more than just an attribute of individual human acts that build the 
community. It is a basic humanistic orientation towards one's fellow human beings. One of Brenda Fassies's latest ditties Umntu Ngumntu Ngabantu (a person is a person through other persons), has helped to popularize what forms the very kernel of Ubuntu (Sebidi 1998).

\section{Methodology}

This is a small scale quantitative survey to elaborate the ubuntu concept further. A survey is one of the most commonly used methods of data collection in social research. The participants were drawn from the university community where I work. Strategically located within the Eastern Cape Province, Walter Sisulu University (WSU)(http://www.wsu.ac.za) straddles a vast spectrum of the urban and rural divide of the region. The University perceives itself a part of a family of African institutions of higher learning, firmly committed to recruiting both national and international academics and students from all countries outside the borders of South Africa. Academics and a section of students from African countries and a handful from South Africa were targeted for the study.

A judgemental sampling technique was used to select the participants. Both national and international academics and students participated in the study. Three hundred (300) questionnaires were distributed amongst them but only 220 responses were received, computed and categorised as follows: Eighty five (85) South African students, Forty seven (47) international students, Sixty one (6I) South African academics and twenty seven (27) international lecturers. The questionnaires did not cater for the categorisation of academics according to their respective ranks. It is worth mentioning that academics in managerial positions did not participate.

Consistent with the aim of the study, the focus of attention was on participants' perceptions of the concept Ubuntu and its relevance to their communities. The survey instrument used in this research was a questionnaire which was administered to participants for systematising data collection. Cantrell et al. (1993) posit that instruments are tied to the purpose of the study and the structure of the design. Five questions were asked. Although single response questions were preferred for their easy processing, unstructured questions were included to allow respondents to justify some of their responses and to allow them more freedom to articulate their feelings. This kind of questionnaire with both structured and unstructured open-ended questions served to structure the conversation between the researcher (who desired information) and the participants (who had agreed to give information). Findings in this paper are summarised below.

\section{Results}

In response to the questionnaire, the following questions were analysed and the results are tabled below:

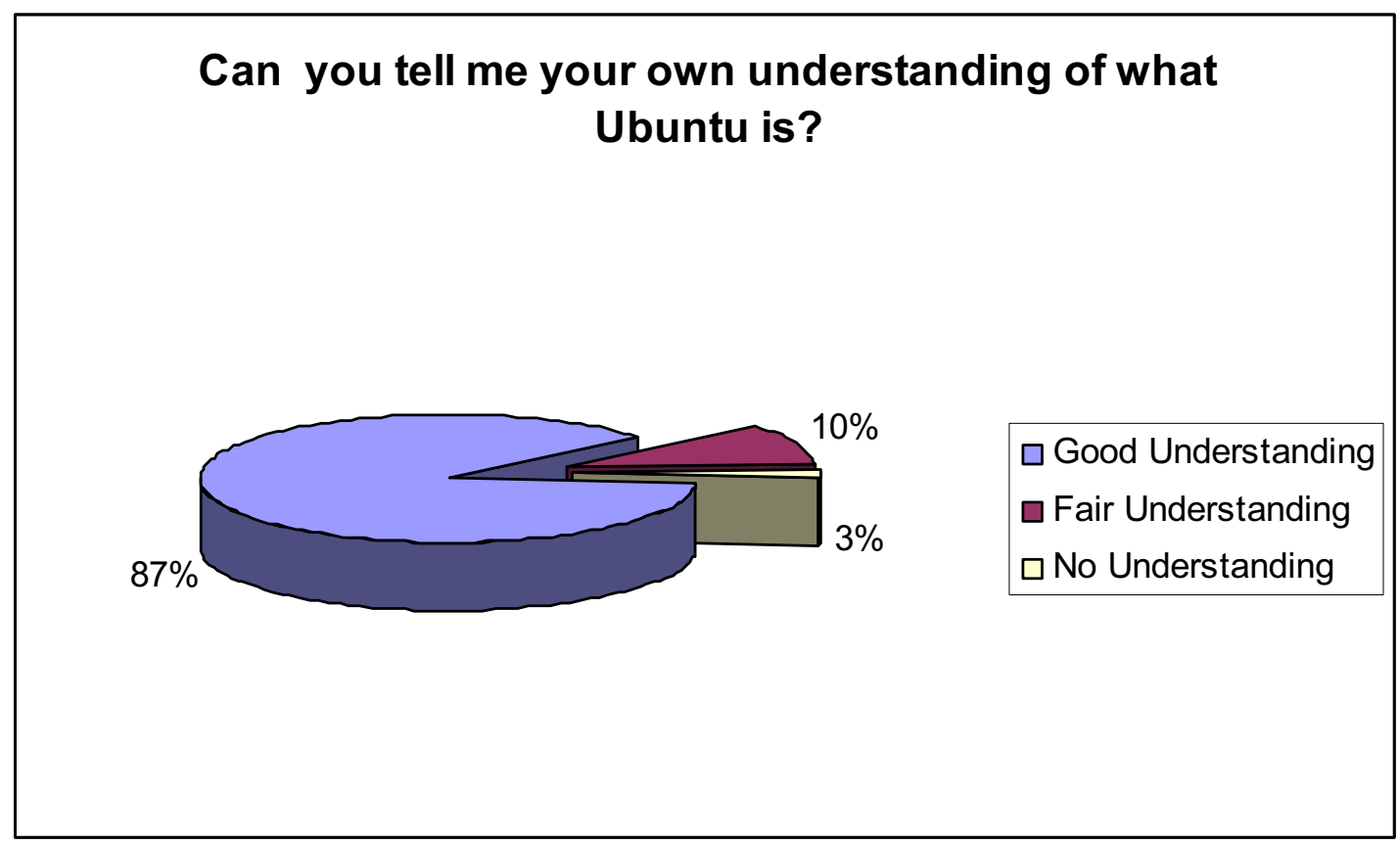

Figure 1 Understanding of Ubuntu 


\section{Is Ubuntu principle efficiently practiced in your community?}

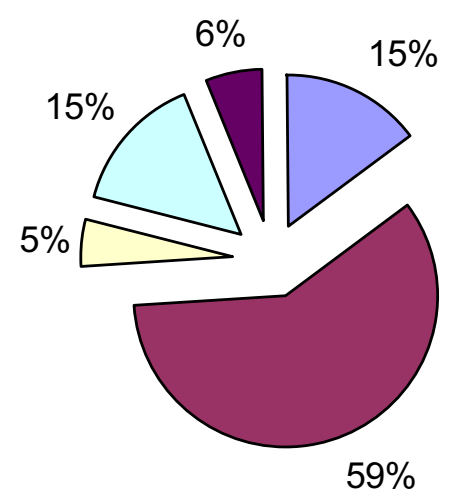

$$
\begin{aligned}
& \square \text { Very Efficient } \\
& \square \text { Efficient } \\
& \square \text { Undecided } \\
& \square \text { Inefficient } \\
& \square \text { Very Ineffient }
\end{aligned}
$$

Figure 2 Practice of Ubuntu in the community

\section{Is there any willingness among people in your community to embrace values of Ubuntu?}

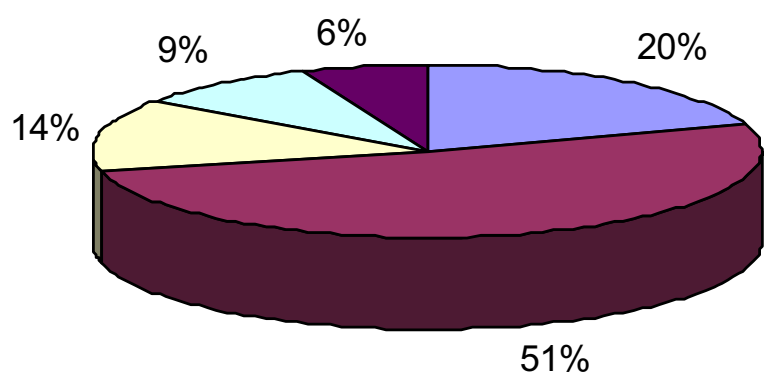

$\square$ Strongly favour

$\square$ Tend to favour

$\square$ No opinion

$\square$ Tend to disfavour

口 Strongly disfavour

Figure 3 Willingness to embrace Ubuntu values in the community 


\section{Are there any problems that prevent your community members from practicing Ubuntu?}

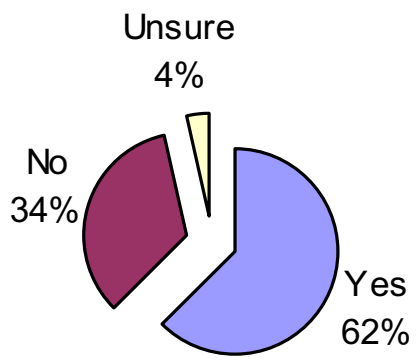

\section{Write any practice that still binds community members together that you believe relates to Ubuntu?}

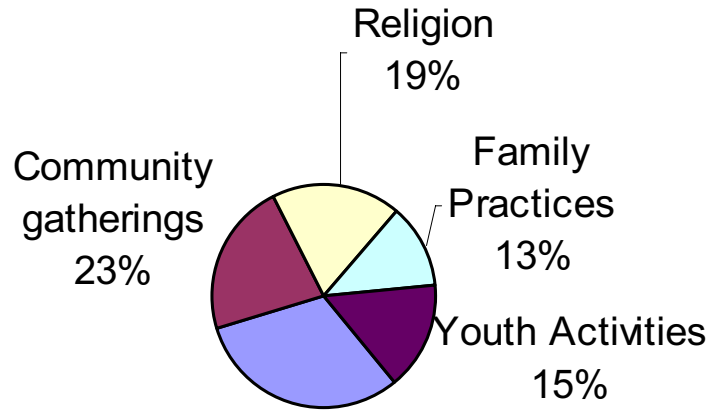

Cultural Activity $30 \%$ $\square$ Cultural Activity

$\square$ Community gatherings

$\square$ Religion

$\square$ Family Practices

- Youth Activities 


\section{Discussions}

The survey revealed that the participants perceived themselves to have a very good understanding of what Ubuntu is. This was shown by a huge percentage of people indicating their good understanding of Ubuntu and its values. Furthermore, it revealed that Ubuntu is still practised although not on a large scale by most communities and moreover, they are still willing to embrace values of Ubuntu. However, the survey also provided a long list of hindrances/obtacles that prevent people from practising cultural activities in their communities as listed below:

- Poverty and lack of resources

- Crime and substance abuse

- Lack of trust among community members

- Foreign cultures and religious beliefs

- Lack of knowledge and motivation

\section{Conclusions and recommendations}

The paper draws on Ubuntu as its theoretical framework. In the context of theoretical structuring, we argue for communitarian principles in a philosophical position that defines a person in terms of social bonds and cultural traditions, rather than through individual traits. The paper contends that traditional African cultural practices are performed by members, clans and relatives in their socio-ethical settings. Examples have been highlighted and supported - to some extent - by research data on how things were (and still are) done in indigenous African settings in which people come together whenever problems arise, where ideas are shared, solutions are sought and found by all community members in a given real-life situation. To re-affirm the constraints that confront strategies aimed at reviving and rekindling the spirit of Ubuntu, the obstacles that hinder cultural practices and communal values such as xenophobia, moral degeneration, crime, religion and individualism have been highlighted. Finally, the paper argues for the restoration of the philosophy of Ubuntu as it encapsulates moral norms and virtues such as kindness, generosity, compassion, benevolence, courtesy, and respect and concerns for others. This author suggests the retrieval of Ubuntu, knowing fully well that African culture, just like all other cultures, has never been static. It is recognised that cultures grow with time. Hence, I do propose that people have to re-adjust to meet new challenges and demands brought about by modernisation.

This paper therefore, recommends the following measures towards the retrieval of Ubuntu:

- The revival of cultural activities. In some communities this is termed Ibuyambo (a Xhosa name for revival).

- The restoration of African culture. African culture is taken to mean the sum total of the ways in which a society preserves, identifies, organises, sustains and express itself.

- The restoration of a shared sense of morality. Within the African societies, there is a shared sense of morality that is similar in many aspects and based on the key concept of Ubuntu.

- The restoration of public morality. In African communities public morality regulates the behaviour and values of both the community and the individual who lives and achieves his or her full humanness within the community.

- The restoration of Ubuntu. Ubuntu includes the values of greeting everyone, sharing, generosity, hospitality, good manners, respect and protecting one's dignity and others' human dignity.

Although I do recommend the restoration of these cultural values, I am conscious of the fact that communities can never practise culture way it used to be practised in the past and culture and traditions are not static but change with time.

\section{References}

Barber, B. (1998). The conquest of politics: Liberal philosophy in democratic times: Princeton, New Jersey: Princeton University Press.

Battle, M. (1996). The ubuntu theology of Desmond Tutu. In: Hulley, L. Kretzchmar, L \& Pato LL (eds.), Archbishop Tutu: Prophetic witness in South Africa. Cape Town: Human \& Rousseau, 93-I05.

Cantrel, D.C. (1993). The practice of social research, $9^{\text {th }}$ Edition. Belmont, California: Wadsworth Publishing.

Daly, M. (1994). A new public ethics: Belmont, California: Wadsworth Publishing

Gyekye, K. (1987). An essay on African philosophical thought: The Akan conceptual scheme. New York: Cambridge University Press.

Gyekye, K. (2002). Person and community in African thought. In: Coetzee PH \& Roux, APJ (eds.), Philosophy from Africa: A text with readings. $2^{\text {nd }}$ Edition. Cape Town: Oxford University Press of Southern Africa, 297-3 I 2

Khoza, R.J. (2005). Let Africa lead. Sunninghill:Vezubuntu.

Letseka, M. (2000). Africana Philosophy and educational discourse. In: Higgs P, Vakalisa, N.C.G, Mda, T.V. and Assie -Lumumba, N.T. (eds.). African Voices in Education. Lansdowne: Juta, I79- 193.

Mbigi, L. (1997). Ubuntu: The dream in African management. Randburg: Knowledge Resources.

Mbiti, J.S. (1970). African religions and philosophy. It $^{\text {st }}$ (ed.). London: Heinemann. 
Ramose, M.B. (2002a). The philosophy of ubuntu and ubuntu as a philosophy: In: Coetzee, P.H. \& Roux, A.P.J. (2002). Philosophy from Africa: A text with readings. Second Edition. Cape Town: Oxford University Press.

Ramose, M.B. (2002b). The ethics of ubuntu. In Coetzee, P.H. and Roux, A.P.J. (eds). Philosophy from Africa: A text with readings. $2^{\text {nd }}$ Edition, Cape Town: Oxford University Press of Southern Africa, 324-330.

Roux, A.P.J. and Coetzee, P.H. (1994). Beyond the question of African philosophy: A selection of papers presented at the International colloquia, Unisa, 304-318.

Sebidi, L.J. (1998). Towards a definition of ubuntu as African humanism. In: Perspectives on 'ubuntu': A tribute to Fedsen.Ed. M.G.Khabela and Z.C. Mzoneli. Alice: Lovedale Press.

Makwanyane, S.V. (1995) (3) SA 39, (CC). 1995 (6) BCLR 665 CC.

Teffo, L.J. (1998). Both/ubuntu as a way forward for contemporary South Africa. Word and Action. 38 (365):3-5.

Teffo, L.J. \& Roux, P.J. (2002). Metaphysical thinking in Africa: Themes in African metaphysics. In: Coetzee P.H. and Roux A.P.J. (2002) Philosophy from Africa: A text with readings: Second Edition. Cape Town: Oxford University Press.

Venter, E. (2004) The notion of ubuntu and communalism in African educational discourse: Studies in philosophy and education. Netherlands: Kluwer Academic Publishers.

Waghid, Y., Van Wyk, B., Adams, F. \& November, L. (eds.) (2005). African (a). philosophy of education. Reconstructions and deconstructions. Matieland: Stellenbosch University Printers. Department of Education Policy Studies (DEPS).

Waliggo, J.M. (2005). Law and public morality in Africa: Legal, philosophical and Cultural issues. The ALRAESA Annual Conference 4-8 ${ }^{\text {th }}$ September 2005. Entebbe: Uganda. 